\title{
Site-specific chemical conjugation of human Fas ligand extracellular domain using trans-cyclooctene - methyltetrazine reactions
}

\author{
Michiro Muraki ${ }^{*}$ and Kiyonori Hirota
}

\begin{abstract}
Background: Fas ligand plays a key role in the human immune system as a major cell death inducing protein. The extracellular domain of human Fas ligand (hFasLECD) triggers apoptosis of malignant cells, and therefore is expected to have substantial potentials in medical biotechnology. However, the current application of this protein to clinical medicine is hampered by a shortage of the benefits relative to the drawbacks including the side-effects in systemic administration. Effective procedures for the engineering of the protein by attaching useful additional functions are required to overcome the problem.
\end{abstract}

Results: A procedure for the site-specific chemical conjugation of hFasLECD with a fluorochrome and functional proteins was devised using an inverse-electron-demand Diels-Alder reaction between trans-cyclooctene group and methyltetrazine group. The conjugations in the present study were attained by using much less molar excess amounts of the compounds to be attached as compared with the conventional chemical modification reactions using maleimide derivatives in the previous study. The isolated conjugates of hFasLECD with sulfo-Cy3, avidin and rabbit lgG Fab' domain presented the functional and the structural integrities of the attached molecules without impairing the specific binding activity toward human Fas receptor extracellular domain.

Conclusions: The present study provided a new fundamental strategy for the production of the engineered hFasLECDs with additional beneficial functions, which will lead to the developments of the improved diagnostic systems and the effective treatment methods of serious diseases by using this protein as a component of novel molecular tools.

Keywords: Human Fas ligand, Extracellular domain, Site-specific conjugation, trans-Cyclooctene, Methyltetrazine, Fluorochrome, Functional protein, Receptor-binding activity

\section{Background}

Fas ligand (FasL) plays a key role in preventing many serious diseases in the human immune system as a major cell death inducing protein $[1,2]$. The extracellular domain of human Fas ligand (hFasLECD) binds to human Fas receptor (hFasR) on the surface membrane of malignant cells and triggers apoptosis of the target cells. Therefore, it is expected that hFasLECD has

\footnotetext{
* Correspondence: m-muraki@aist.go.jp

Biomedical Research Institute, National Institute of Advanced Industrial Science and Technology (AIST), Central 6, 1-1-1 Higashi, Tsukuba, Ibaraki 305-8566, Japan
}

substantial promising potentials in the field of medical biotechnology [3, 4]. The intravenous administration of a large amount of hFasLECD produced in Pichia pastoris caused a serious liver injury by acute hepatitis. However, the specific activity of the hFasLECD sample was at least 20 times higher than an anti-mouse FasR agonistic monoclonal antibody, Jo2, in inducing apoptosis against FasR overexpressing mouse cells, and showed much less toxicity with regard to the liver failure in vivo [5]. To overcome the above mentioned problem, numerous studies for delivering the protein specifically toward the target cells have been made by exploiting the 
gene-fusion technology using the genes of single chain variable fragments of the cell-surface antigen recognizing antibodies and the extracellular domains of cytokines as the fusion components [6-10]. On the other hand, the administration of many cytotoxic drugs, including the ones in clinical uses, is known to significantly affect the number of cell-surface hFasR, which determines the susceptibility to apoptosis execution by hFasL [11-14]. Accordingly, engineered molecules, including antagonistic monoclonal antibodies against the extracellular domain of hFasR (hFasRECD) such as ZB4, have been also developed as useful molecular tools for the detection of cell-surface hFasR $[15,16]$.

Site-specific chemical conjugation utilizing a reactive tag residue to install chemical groups by covalent additions is another potent technology for engineering proteins to attach new functionalities, which are not available in the original molecules $[17,18]$. In previous studies, one of the authors has developed an hFasLECD derivative containing a reactive cysteine residue in its $\mathrm{N}$ terminal tag sequence [19], and prepared a functional fluorescent derivative as a prototype engineered molecule by direct chemical modification of the cysteine residue using a large excess molar amount of fluorescein 5-maleimide, without impairing original hFasRECD binding activity [20]. However, the free thiol groups in the cysteine residues tend to lose the reactivity by oxidative disulfide-bridges formation, and the maleimidegroups in the fluorochrome labeling reagents can be readily inactivated by hydrolysis, under aqueous buffer conditions of physiological pH. Recently, a powerful means for chemical conjugations, which employs an inverse-electron-demand Diels-Alder reaction between trans-cyclooctene (TCO) group and methyltetrazine (MTZ) group, has been developed as an efficient tool in the field of bioorthogonal click chemistry [21], and a variety of relevant chemical reagents became commercially available. TCO and MTZ groups are fairly stable in physiological aqueous buffer solutions, and the conjugation reaction between them can proceed with exceptionally fast kinetics and high selectivity [22, 23]. This makes the reaction attractive for the applications in which only a limiting amount of molecules to be conjugated are generally available, such as the cases using expensive low molecular-weight compounds or precious functional proteins. However, in spite of its potential usefulness, the behaviors in actual conjugation events are not always well documented yet.

In this study, in order to seek the possibility of extending the functionalities to be attached using a less molar excess amount of modification reagents, sitespecific chemical conjugations of a hFasLECD derivative were investigated using the TCO - MTZ cycloaddition reaction. Sulfo-Cy3 fluorochrome derivatives, an avidin derivative and a rabbit Fab' domain derivative were each employed as a representative molecule of low molecular-weight compounds, protein molecules modified with multiple reactive groups and protein molecules containing a single reactive group, respectively. The isolated samples of the conjugates were characterized for their functional and structural integrities of both components in the conjugates using spectroscopic measurements and detection of complex formation with human Fas receptor extracellular domain-human $\mathrm{IgG}_{1} \mathrm{Fc}$ domain fusion protein (hFasRECD-Fc) as well as each individual specific binder.

\section{Results}

\section{Conjugation design and procedures}

An inverse-electron-demand Diels-Alder reaction between TCO- and MTZ-groups, which proceeds at room temperature with the generation of nitrogen gas as the sole side product, was used for the conjugation reaction (Fig. 1a). In Fig. 1b, the schematic structures of the compounds used in the TCO - MTZ conjugation reactions in this study are summarized with each detailed chemical structure of the MTZ- or the TCO-group containing spacer arm. The conjugations were performed either between hFasLECD-TCO and an MTZ-group containing compound, or between hFasLECD-MTZ and a TCOgroup containing compound. For the preparation of hFasLECD-TCO and hFasLECD-MTZ, the reactive cysteine residue in the $\mathrm{N}$-terminal tag sequence of $\mathrm{hFa}$ sLECD molecule was chemically modified with a large excess molar amount of trans-cyclooctene- $\mathrm{PEG}_{3}$-maleimide (TCO-PEG3-MAL) and methyltetrazine-PEG ${ }_{4}$ maleimide (MTZ-PEG4-MAL) reagents, respectively. In this study, NFK3G1CG4-hFasLECD, a revised hFasLECD derivative containing three additional lysine residues following the DYKDDDDK (FLAG) tag sequence as compared to NFG1CG4-hFasLECD [19] was exploited for the derivatization (Additional file 1a). NFK3G1CG4hFasLECD was produced using a secretory expression system in $P$. pastoris as described in the previous papers $[24,25]$. To date, the tertiary structure of a complex between hFasLECD and human decoy receptor 3 (DcR3) has been determined by X-ray crystallography, which serves as a model for hFasLECD - hFasRECD complex [26]. From a viewpoint of three-dimensional structure, the attachment site of the tag sequence was designed to locate not proximal to the receptor binding interface in order to avoid the interference with the specific recognition of hFasRECD (Additional file 1b). The additional lysine residues in the tag sequence were introduced to increase the isolelectric point value for making the isolation of the hFasLECD derivative from other impurities in the culture medium easier than the case of the 

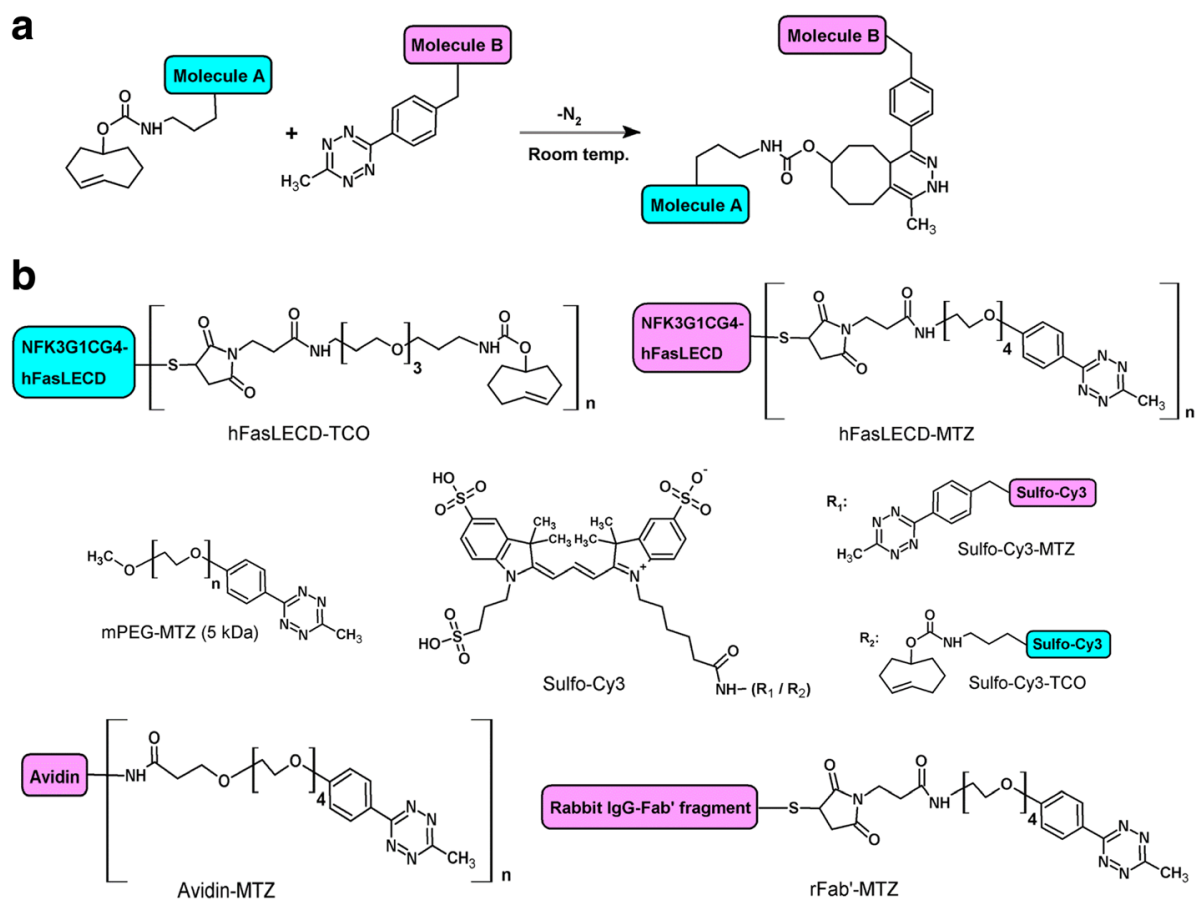

Fig. 1 Schematic chemical structures of molecules relevant to the conjugation reactions between TCO- and MTZ-groups. a General conjugation reaction scheme. $\mathbf{b}$ Compounds used as the components in the TCO - MTZ conjugation reactions. With respect to the protein molecules, only TCO- and MTZ-group containing spacer arms are drawn as detailed chemical structures. The " $\mathrm{n}$ " after the square brackets indicates either a repeat of units or the possible multiple conjugations

original derivative at the initial purification step using a simple stepwise salt-gradient elution (Additional file 1c).

As a preliminary evaluation of the conjugation efficiency using the TCO - MTZ reaction, the percentage of the reactive TCO-groups, introduced by the modification of NFK3G1CG4-hFasLECD with a large excess molar amount of TCO-PEG3-MAL, was evaluated by the reaction of hFasLECD-TCO with 0.5, 1.0, 1.1 and $1.5 \mathrm{M}$ excess amounts of methyltetrazine conjugated mPEG(5 kDa) (mPEG-MTZ) (Fig. 1b). The ratio of the conjugated product to non-conjugated sample remained almost the same among the experiments using from 1.0 to $1.5 \mathrm{M}$ excess amounts of mPEGMTZ reagent (Fig. 2). This suggested that the use of 1.0-1.5 M excess amounts of mPEG-MTZ was enough to saturate the reaction efficiency. The maximum percentage of the conjugated product was estimated to be approximately $80 \%$ by a densitometry analysis of the protein bands on the SDS-PAGE gel.

\section{Preparation and characterization of sulfo-Cy3-TM- hFasLECD and sulfo-Cy3-MT-hFasLECD}

The conjugation reactions were conducted using 1.31.4 $\mathrm{M}$ excess amounts of the sulfo-Cy3 reagents, i.e. sulfo-Cy3-methyltetrazine (Sulfo-Cy3-MTZ) and sulfoCy3-trans-cyclooctene (Sulfo-Cy3-TCO) (Fig. 1b), relative to either hFasLECD-TCO or hFasLECD-MTZ. The reaction mixtures for generating the two alternative types of sulfo-Cy3-hFasLECD conjugates were analyzed by SDS-PAGE (Fig. 3a) and the high-performance sizeexclusion chromatography (Fig. 3b, left panels). The SDS-PAGE analysis showed that the protein bands of both reaction mixtures consisted of a single major dense band at around 21-22 kDa and some other minor bands. The high-performance size-exclusion chromatography analysis of the reaction mixtures presented a single major peak showing the absorbance at both $280 \mathrm{~nm}$ and $550 \mathrm{~nm}$, and the retention time of 19.2-19.3 $\mathrm{min}$, in either case. These results indicated that the reaction products were nearly homogeneous. In Fig. 3b (right panels), the chromatography profiles about the final samples after purification are shown. The ratios of the peak absorbance at $550 \mathrm{~nm}$ to that at $280 \mathrm{~nm}$ concerning the purified samples after fractionation were 2.6 and 2.8 with regard to the sulfo-Cy3-MTZ conjugated hFasLECDTCO (Sulfo-Cy3-MT-hFasLECD) and the sulfo-Cy3TCO conjugated hFasLECD-MTZ (Sulfo-Cy3-TM-hFasLECD), respectively. This suggested that an effective conjugation of a sulfo-Cy3 moiety to the hFasLECD derivative was attained using even only $1.3-1.4 \mathrm{M}$ excess amounts of the modification reagents in either case. In Fig. 4, ultraviolet-visible (UV-Vis) absorption spectra and fluorescence emission spectra of the purified conjugate samples are presented. Both samples showed the spectra 


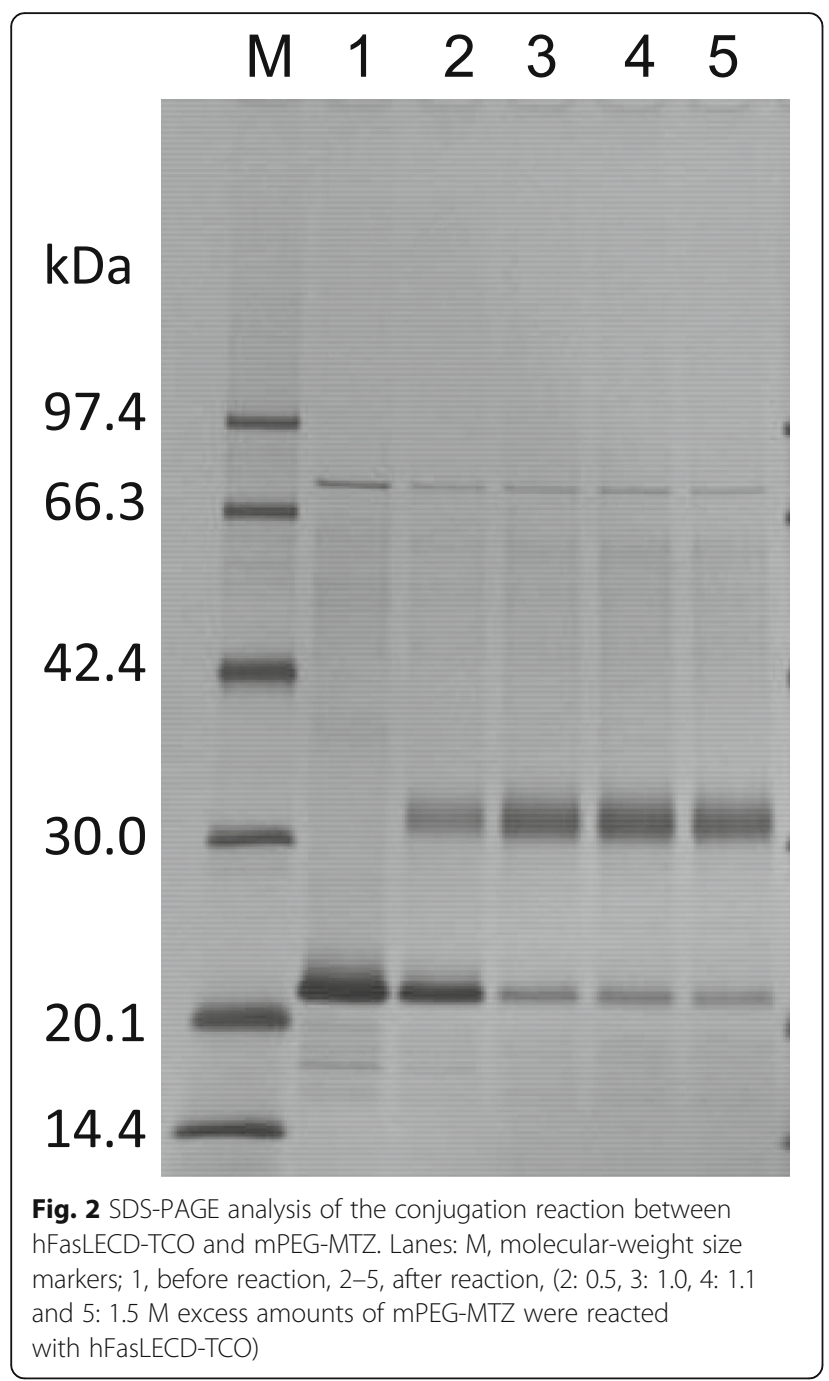

with the maximum absorption peak at 551-552 $\mathrm{nm}$ and the fluorescence emission peak at $570 \mathrm{~nm}$, which are the functional characteristics of sulfo-Cy3 group. The estimated conjugation number of the fluorochrome per a single hFasLECD trimer, calculated from the ratio of the absorbance at $280 \mathrm{~nm}$ to that at $552 \mathrm{~nm}$, were 1.5 and 1.6 for Sulfo-Cy3-MT-hFasLECD and Sulfo-Cy3-TMhFasLECD, respectively.

The capability of the Sulfo-Cy3-hFasLECDs to form a specific complex with hFasRECD-Fc was examined using a receptor-mediated co-immunoprecipitation experiment and the high-performance size-exclusion chromatography analysis. Both conjugate samples were shown to retain a strong binding activity toward hFasRECD-Fc using the co-immunoprecipitation experiments (Fig. 5a). The major peaks showing the absorbance of $550 \mathrm{~nm}$ appeared at an earlier position than the retention time of hFasRECD-Fc showing $280 \mathrm{~nm}$ absorbance alone (Additional file 2), in both cases. This together with the non-existence of a large peak of the free ligand component in the size-exclusion chromatography profiles clearly showed the complex formation (Fig. 5b). However, a small difference in the chromatography profile was detected between Sulfo-Cy3-MT-hFasLECD (upper) and Sulfo-Cy3-TM-hFasLECD (lower). A slightly larger delay in the peak retention time of the absorbance at $280 \mathrm{~nm}$ from that at $550 \mathrm{~nm}$, coincided with the existence of a higher peak at the elution position of the free ligand component, was observed for Sulfo-Cy3-TMhFasLECD as compared with Sulfo-Cy3-MT-hFasLECD. This result suggested a stronger binding activity of SulfoCy3-MT-hFasLECD than Sulfo-Cy3-TM-hFasLECD toward hFasRECD-Fc. Consequently, hFasLECD-TCO was selected as the component molecule in the following conjugation experiments with functional proteins.

\section{Isolation of avidin-hFasLECD and rFab'-hFasLECDs}

A high-performance size-exclusion chromatography was used for the evaluation of the progress of the conjugation reaction between hFasLECD-TCO and the MTZgroup(s) containing derivatives of proteins. The AvidinMTZ sample showing a single peak in the highperformance size-exclusion chromatography (Fig. 6, panel a) was used for the conjugation with hFasLECD-TCO. It was reasonable to consider that the Avidin-MTZ molecule possessed multiple MTZ groups (Fig. 1b), since the sample was synthesized by the reaction of native avidin, existing as a homotetramer containing nine lysine residues per monomer unit, with eightfold molar excess amount of methyltetrazine- $\mathrm{PEG}_{4}$ sulfo-N-hydroxysuccinimide ester (MTZ-PEG4-sNHS). As a trial conjugation experiment, a series (1.0, 1.2, 1.5 and 3.0 M excess amounts) of Avidin-MTZ were reacted with hFasLECD-TCO to examine the effect of molar ratio on the product profile in the reaction mixture. In Fig. 6 (panels $b-e$ ), the profile of each reaction mixture in the high-performance size-exclusion chromatography is shown. The essential pattern of the chromatography profiles among them resembled to each other. Of note, a distinct peak (marked with an asterisk in the Figure panels) with the retention time of 16.69-16.71 min was always appeared. Judging from the retention time, this peak was thought to contain the one to one conjugate between avidin-MTZ and hFasLECD-TCO. The corresponding peak fraction sample was isolated as a single peak from the reaction mixture after quenching with an excess amount of trans-cyclooctene-amine hydrochloride salt (TCO-Amine) (Fig. 7).

On the other hand, the rFab'-MTZ molecule was considered to possess a single MTZ group (Fig. 1b), since it was synthesized by the modification of the terminal single cysteine residue with a large excess molar amount of MTZ-PEG4-MAL. A series (1.0, 2.0, 3.0 and $5.0 \mathrm{M}$ excess amounts) of the purified rFab'-MTZ sample 


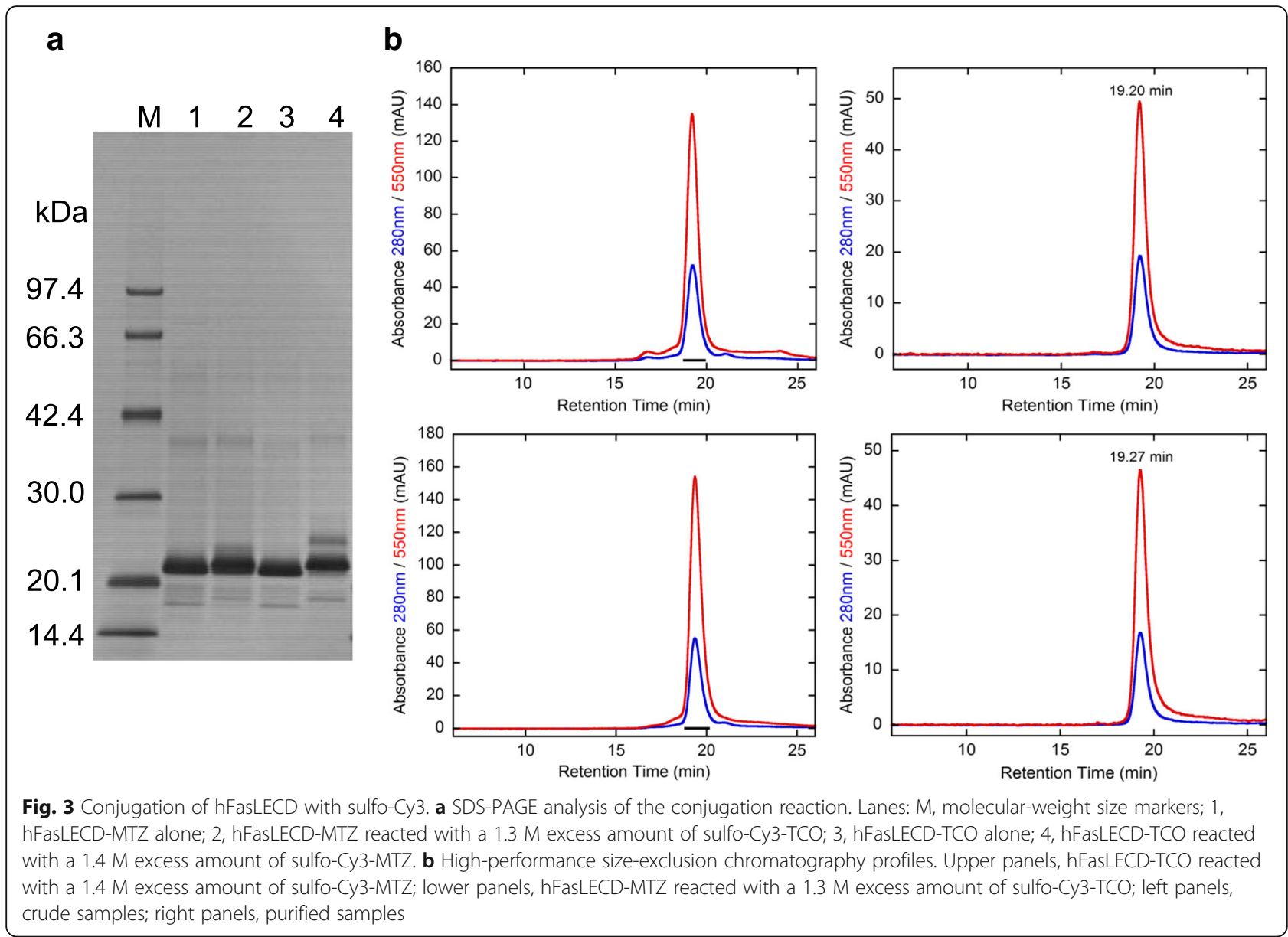

showing a single peak in the high-performance sizeexclusion chromatography analysis (Fig. 8, panel a) were used for the trial conjugation reactions with hFasLECDTCO to examine the effect of the molar ratio on the product profile (Fig. 8, panels $\mathrm{b}-\mathrm{e}$ ). The chromatography profile significantly depended on the molar ratio of rFab'-MTZ relative to hFasLECD-TCO. Three distinct peaks (designated as peaks 1,2 and 3 according to the numbering in the Fig. 8, panels $\mathrm{b}-$ e) gradually emerged as the molar excess amount value of rFab'-
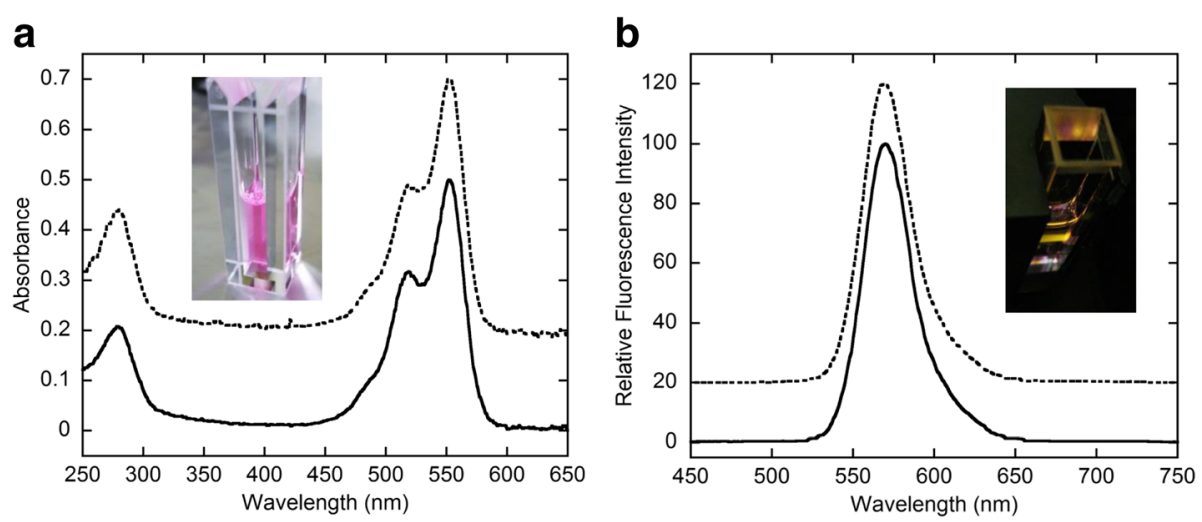

Fig. 4 Spectroscopic analysis of sulfo-Cy3 conjugated hFasLECDs. Dot lines, Sulfo-Cy3-MT-hFasLECD; solid lines, Sulfo-Cy3-TM-hFasLECD. a UV-Vis spectra. The absorbance of Sulfo-Cy3-MT-hFasLECD was expressed as values of the experimental data plus 0.2. Insert, an appearance under white light. b Fluorescence emission spectra excited at $552 \mathrm{~nm}$. The relative fluorescence intensity of Sulfo-Cy3-MT-hFasLECD was expressed as values of the experimental data plus 20. Insert, a fluorescence emission observed in the measurement cuvette 

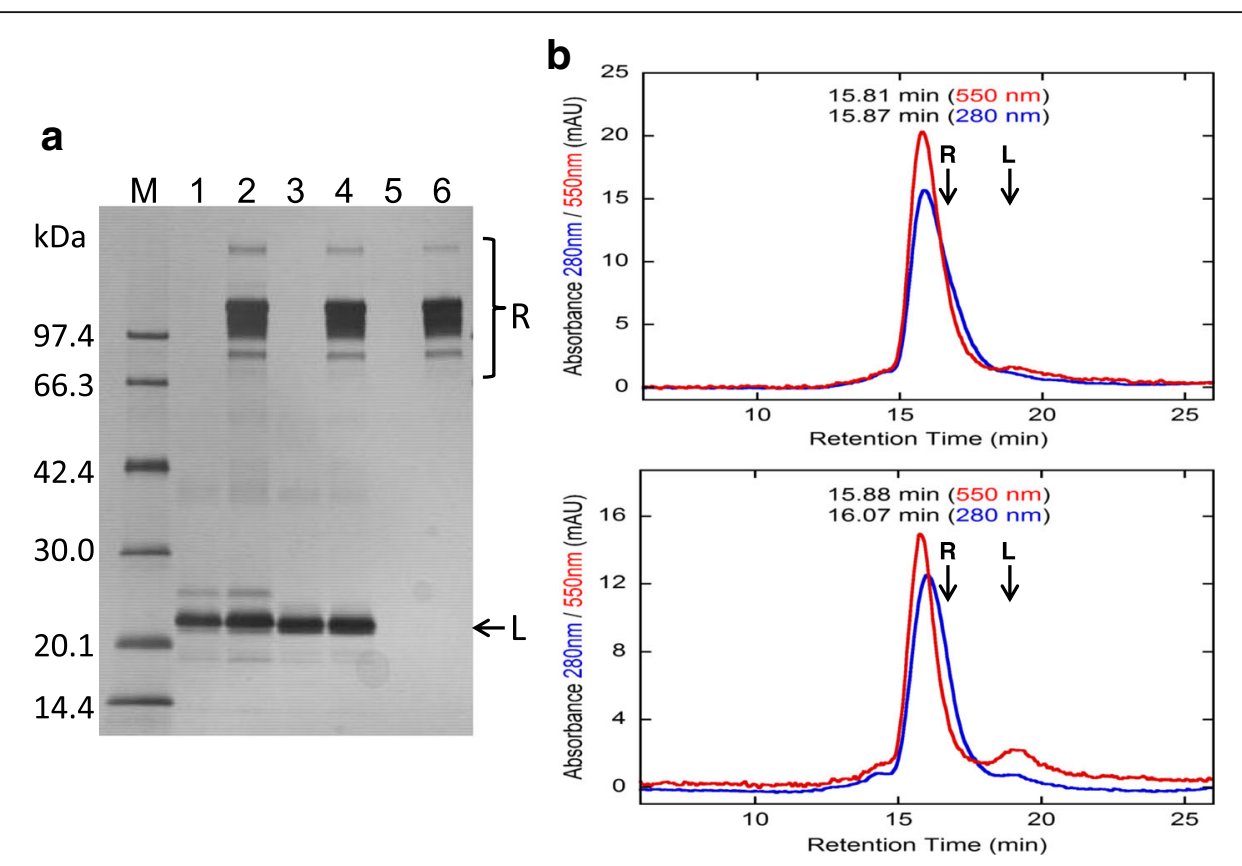

Fig. 5 Complex formation of sulfo-Cy3 conjugated hFasLECDs with hFasRECD-FC. L and R indicate the positions of sulfo-Cy3 conjugated hFasLECDs and hFasRECD-Fc, respectively. a SDS-PAGE analysis of the receptor mediated co-immunoprecipitation. Lanes: M, molecular-weight size markers; 1 and 2, sulfo-Cy3-MT-hFasLECD; 3 and 4, sulfo-Cy3-TM-hFasLECD; 5 and 6, buffer; 1 and 3, purified samples; 5, buffer alone sample; 2, 4 and 6, co-immunoprecipitated materials. b High-performance size-exclusion chromatography profiles. The mixtures of sulfo-Cy3 conjugated hFasLECDs (7.5 $\mu \mathrm{g}$ each) and hFasRECD-Fc (19.4 $\mathrm{g}$ each) were analyzed. Upper panel, sulfo-Cy3-MT-hFasLECD; lower panel, sulfo-Cy3-TM-hFasLECD
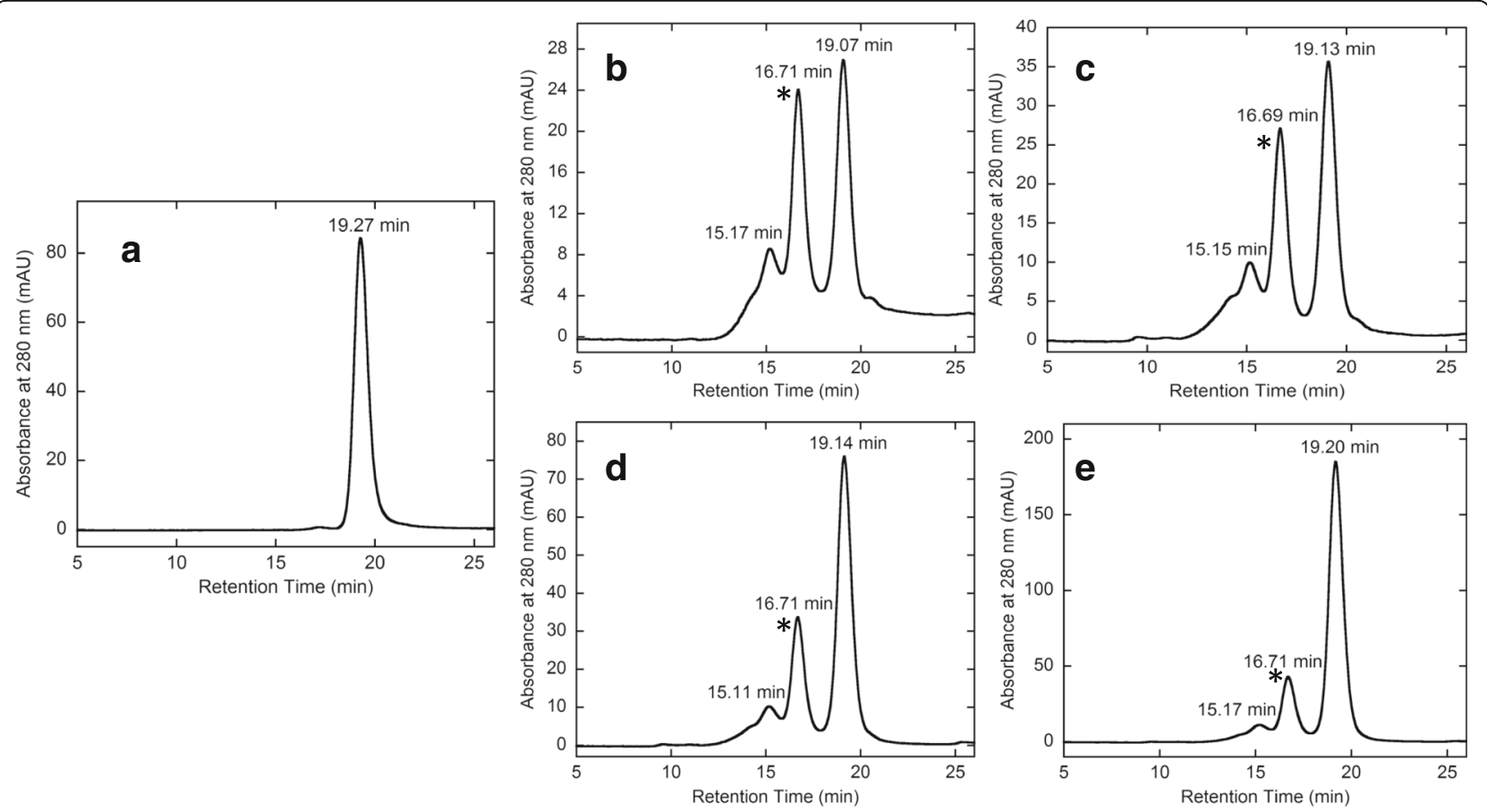

Fig. 6 Conjugation reaction of Avidin-MTZ and hFasLECD-TCO analyzed by high-performance size-exclusion chromatography. Panels: a, AvidinMTZ alone; b-e, reaction mixtures (b: 1.0, c: 1.2, d: 1.5 and e: $3.0 \mathrm{M}$ excess amounts of Avidin-MTZ were reacted with hFasLECD-TCO). Retention time of each peak is shown 

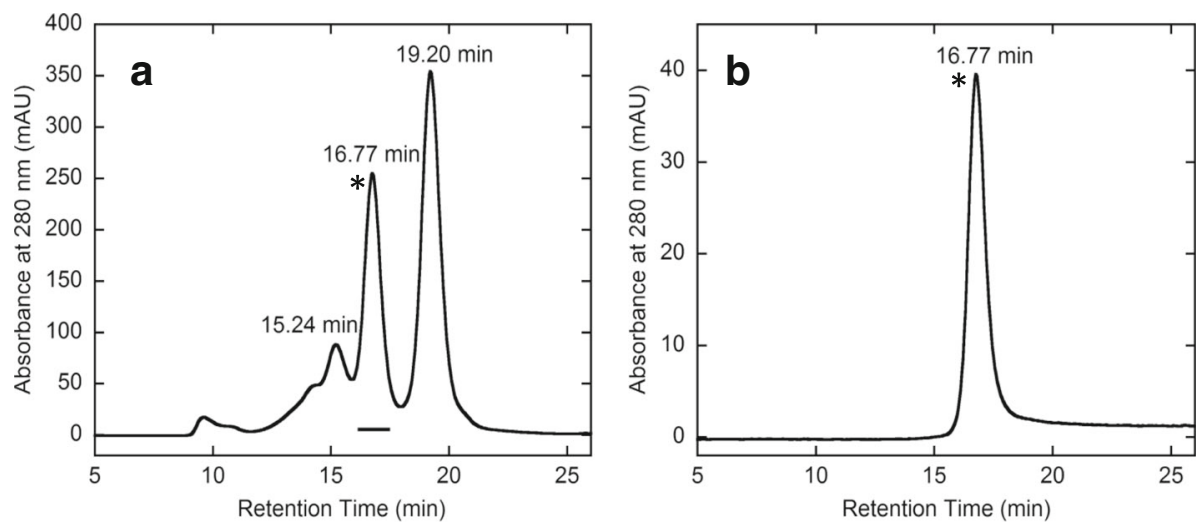

Fig. 7 Isolation of Avidin-hFasLECD conjugate by high-performance size-exclusion chromatography. Panels: a, reaction mixture after quenching with TCO-Amine. The peak fraction shown in under bar was collected; $\mathbf{b}$, isolated sample

MTZ increased. As judged by the decrease in the retention time showing the increase in the molecular weight in the order of peak $3>$ peak $2>$ peak 1 , the emergence of these peaks was considered to correspond to the single, double and triple conjugation of rFab'-MTZ per a single hFasLECD-TCO timer molecule, respectively. Among them, a single peak fraction consisting of peak 1 and a combined fraction mainly composed of the peaks 2 and 3 were isolated after quenching with an excess amount of
methyltetrazine-PEG4-amine hydrochloride salt (MTZPEG4-Amine) (Fig. 9).

\section{Characterization of the isolated samples of avidin- hFasLECD and rFab'-hFasLECDs}

In Fig. 10, panels a and b present the results of receptormediated and antibody-mediated co-immunoprecipitation experiments using hFasRECD-Fc and biotin-conjugated goat anti-rabbit IgG H\&L as the specific binding linker between the examined molecules and Protein G-
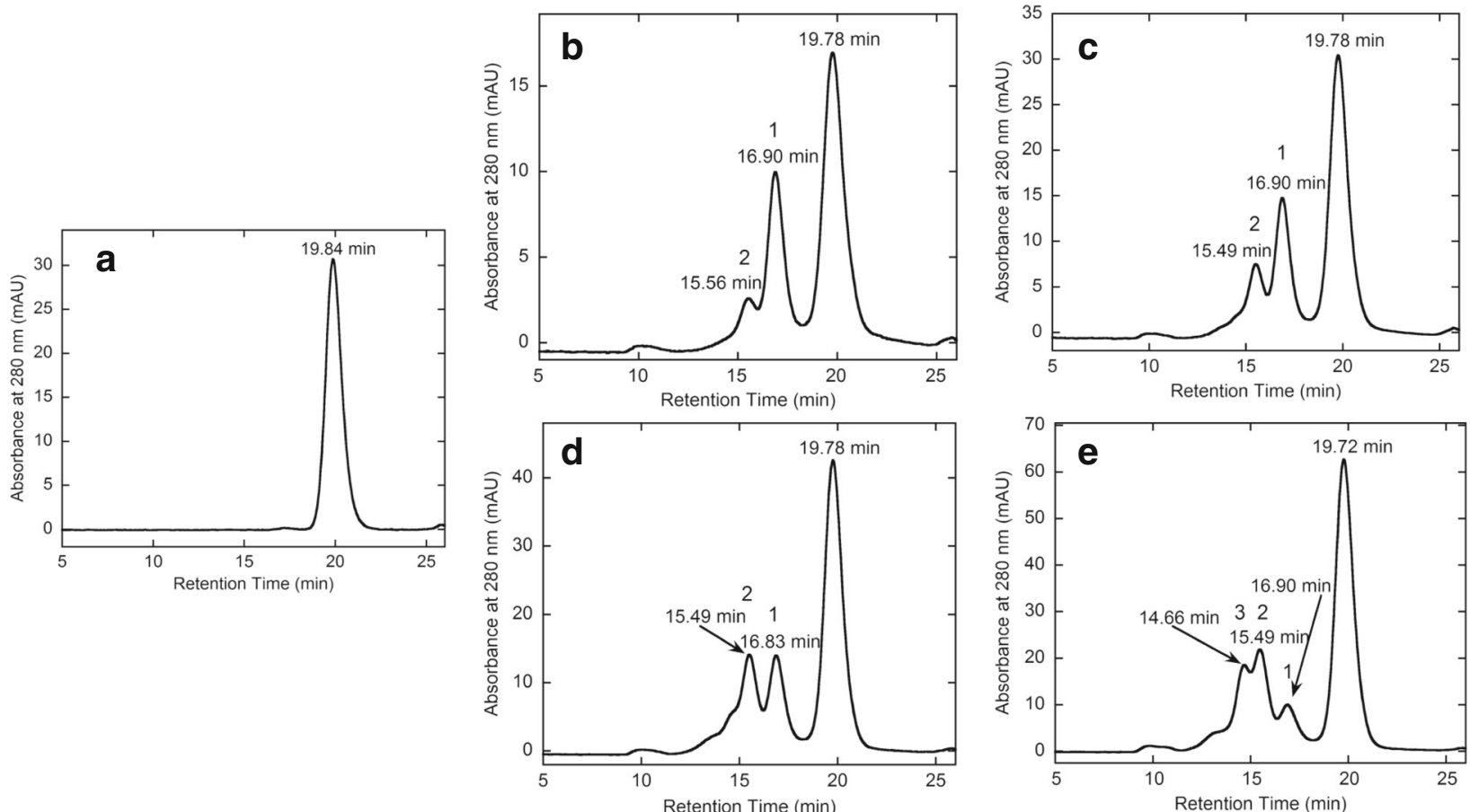

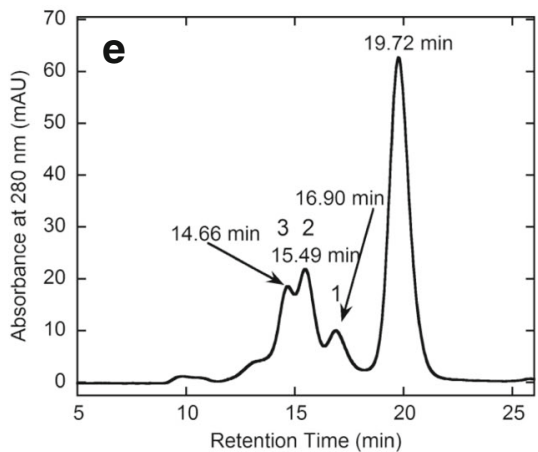

Fig. 8 Conjugation reaction of rFab'-MTZ and hFasLECD-TCO analyzed by high-performance size-exclusion chromatography. Panels: a, rFab-MTZ alone; b-e, reaction mixtures $(\mathbf{b}, 1.0 ; \mathbf{c}, 2.0 ; \mathbf{d}, 3.0$ and e $5.0 \mathrm{M}$ excess amounts of rFab'-MTZ were reacted with hFasLECD-TCO). Retention time of each peak is shown 

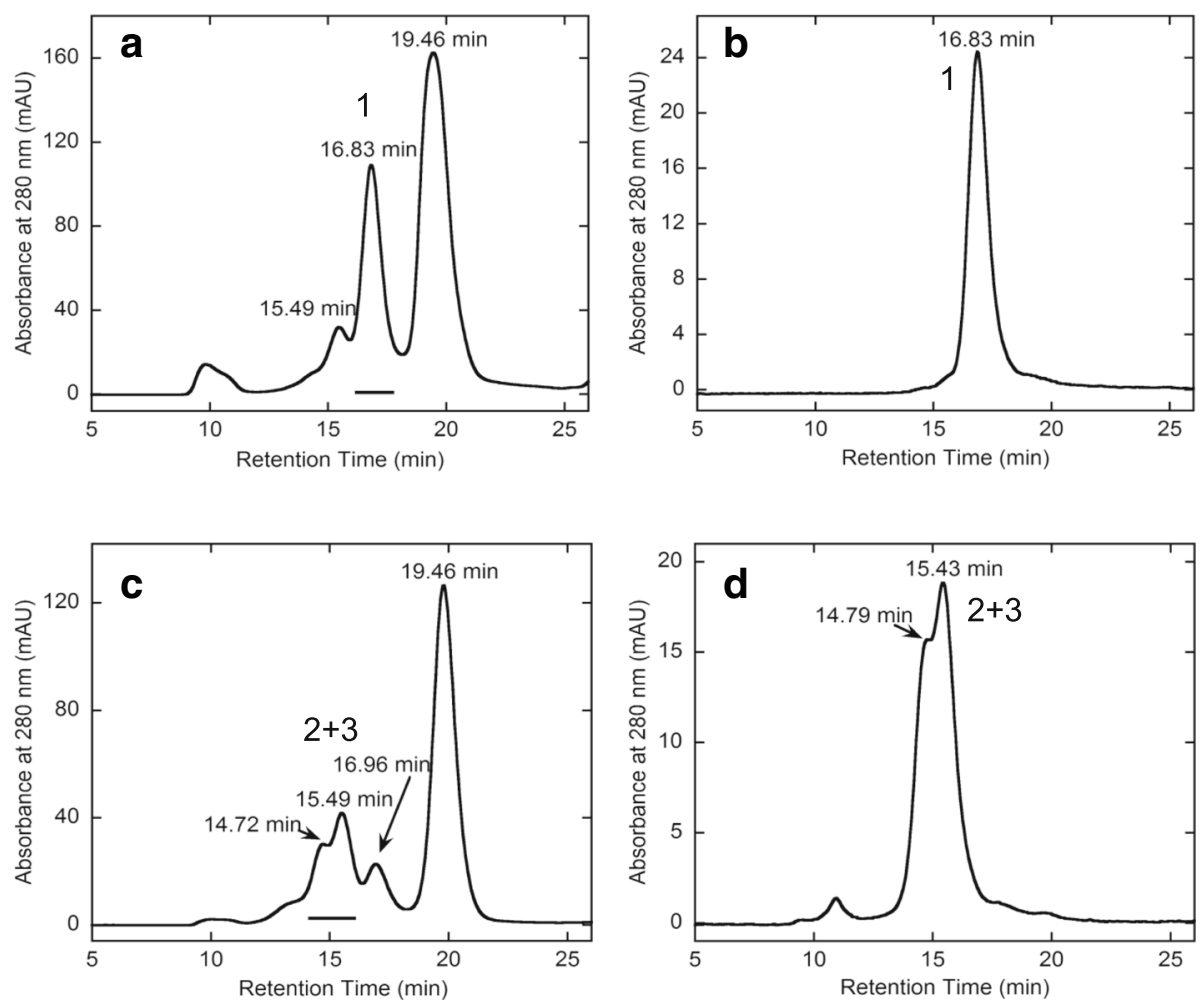

Fig. 9 Isolation of rFab'-hFasLECD conjugates by high-performance size-exclusion chromatography. Panels: a and c, reaction mixture after quenching with MTZ-PEG4-Amine. (a, 1.0 M excess amount of rFab'-MTZ; $\mathbf{c}, 5.0 \mathrm{M}$ excess amount of rFab'-MTZ); $\mathbf{b}$, isolated sample from a; $\mathbf{d}$, isolated sample from $\mathbf{c}$. Retention time of each peak is shown

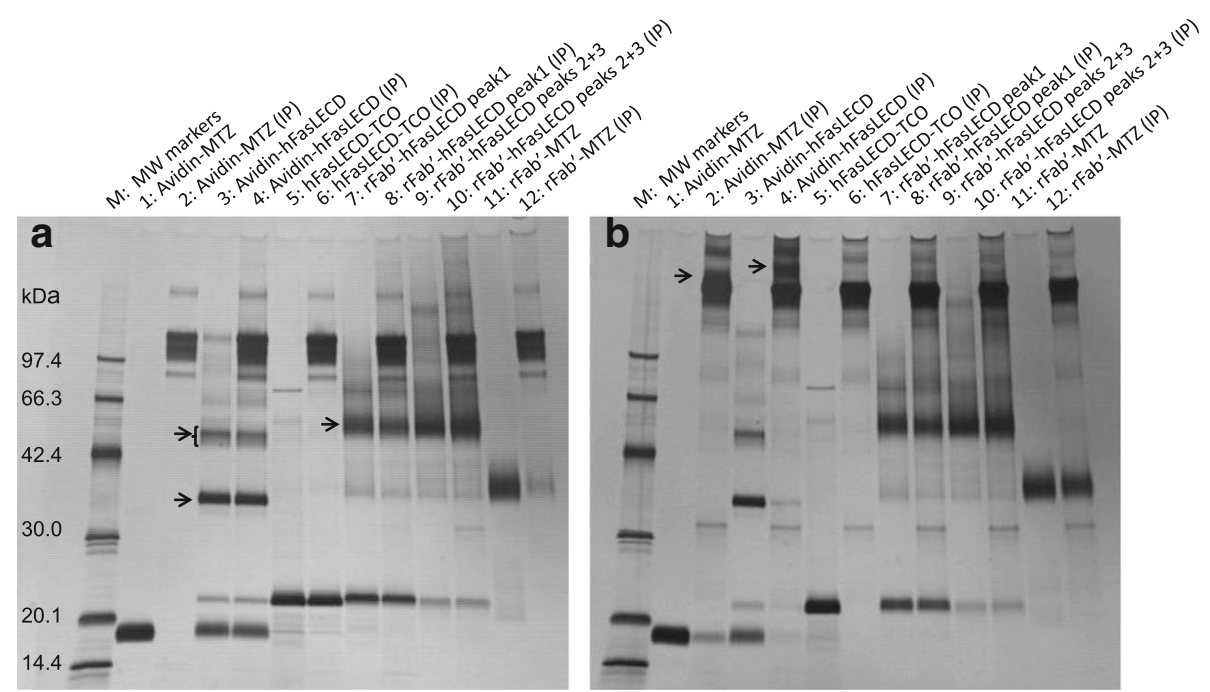

Fig. 10 SDS-PAGE analysis of co-immunoprecipitation experiments under non-reducing condition. Panels: a, receptor-mediated co-immunoprecipitation using hFasRECD-Fc; b, antibody-mediated co-immunoprecipitation using biotin conjugated goat anti-rabbit IgG H\&L. Lanes (in both panels): M, molecular-weight size markers; 1 and 2, Avidin-MTZ alone; 3 and 4, Avidin-hFasLECD conjugate; 5 and 6, hFasLECDTCO alone; 7 and 8, rFab'-hFasLECD conjugate (the peak 1 fraction); 9 and 10, rFab'-hFasLECD conjugate (the combined fractions of peaks 2 and 3); 11 and 12, rFab'-MTZ alone; 1, 3, 5, 7, 9 and 11, examined samples; 2, 4, 6, 8, 10 and 12, precipitated materials (IP) 
conjugated magnetic beads, respectively. Each pair of the examined samples and the corresponding precipitated materials was arranged in parallel and analyzed using a non-reducing SDS-PAGE. Avidin-MTZ (lane 1), hFasLECD-TCO (lane 5) and rFab'-MTZ (lane 11) migrated at the positions of approximately $17 \mathrm{kDa}, 21 \mathrm{kDa}$ and $40 \mathrm{kDa}$, respectively. The isolated sample of avidinhFasLECD conjugate was resolved into several discrete bands (lane 3).

The multiple bands were considered to be arising from the fact that non-denatured avidin-MTZ and nondenatured hFasLECD-TCO existed as a homotetramer and a homotrimer, respectively. Both of them should be dissociated into identical subunits under the denaturing SDS-PAGE condition. Judged by the molecular weights, the densest band at the position between the molecularweight markers of $30.0 \mathrm{kDa}$ and $42.4 \mathrm{kDa}$ (the lower arrow in lane 3 of panel a) was considered to be the major conjugation product consisted of one avidin subunit and one hFasLECD subunit. The broad, weaker band migrated between $42.4 \mathrm{kDa}$ and $66.3 \mathrm{kDa}$ (the upper arrow in lane 3 of panel a) was thought to be the conjugation product consisted of one avidin subunit and two hFasLECD subunits, in which some conformational variations to affect the migration position of the band can exist depending on the attachment sites on the avidin subunits. On the other hand, rFab'-MTZ existed as a monomer protein, and therefore the broad, major band (the arrow in lane 7 of panel a) migrated between the positions of molecular-weight markers of $42.4 \mathrm{kDa}$ and $66.3 \mathrm{kDa}$ was considered to be the one to one conjugation product between the rFab' domain and the $\mathrm{hFa}$ sLECD subunit (lanes 7 and 9 in both panels).

In the co-immunoprecipitation experiment using hFasRECD-Fc as the specific binder (Fig. 10, panel a), all the conjugated samples and hFasLECD-TCO alone sample were precipitated (lanes 4, 6, 8 and 10), indicating the specific binding of the hFasLECD components to hFasRECD-Fc. This showed the functional integrity of the hFasLECD components in the conjugated samples. Avidin-MTZ alone sample did not react at all as expected (lane 2). A weak signal was also observed for Fab'-MTZ alone sample (lane 12), which should be ascribed to the specific, but weak direct interaction between rabbit Fab' domain and Protein G [27]. On the other hand, in the experiment using biotin conjugated goat anti-rabbit IgG H\&L as the specific binder (Fig. 10, panel b), rFab' conjugated hFasLECD samples and rFab'MTZ alone sample showed strong signals (lanes 8, 10 and 12), indicating the specific binding of the rFab' domains to the antibody. This presented the structural integrity of Fab' domains in the conjugates, since the antibody was isolated by affinity chromatography using the antigen coupled to agarose beads, and then conjugated to biotin [28]. The precipitation of Avidin-MTZ alone sample (lane 2) and avidinhFasLECD conjugate sample (lane 4) was also considered to occur. However, most of the precipitated product migrated at a higher position than the antibody (the arrows in lanes 2 and 4 of panel b), and only weak bands were observed at each original positions of the major bands of the examined samples. This retarded migration can be explained by the formation of a large molecular-weight complex between the dissociated monomeric avidin subunits and the multiple biotin moieties pre-conjugated to the antibody. This type of complex was also reported to be fairly stable under the non-reducing SDS-PAGE condition in a capillary gel electrophoresis [29]. As expected, hFasLECD-TCO alone sample did not precipitate at all (lane 6).

The biotin moiety binding of the isolated avidinhFasLECD sample under the non-denatured condition was examined by mixing it with ATTO495-Biotin in a buffer solution of $\mathrm{pH} 7.5$ without any detergent. As shown in Fig. 11, both an emergence of significant absorption peak with the maximum at $479 \mathrm{~nm}$ (green line) not detected for the conjugated protein sample alone (blue line) and a remarkable increase in the absorbance peak at $272 \mathrm{~nm}$ as compared to the conjugated sample alone (blue line) were observed for the complex sample (green line). The result evidently showed the existence of biotin binding activity of the isolated avidinhFasLECD conjugate sample in a native state under the physiological $\mathrm{pH}$ buffer condition. In this binding event, a significant shift of the maximum absorption wavelength of the complex ( $479 \mathrm{~nm}$, green line) from that of

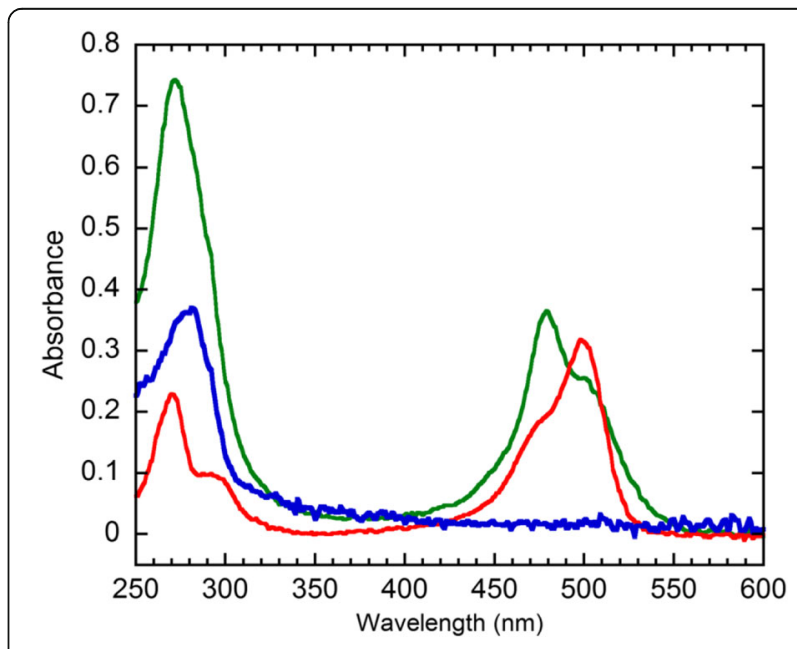

Fig. 11 Detection of complex formation between Avidin-hFasLECD conjugate and ATTO495-Biotin. Lines: green, isolated complex between Avidin-hFasLECD conjugate and ATTO495-Biotin; blue, Avidin-hFasLECD conjugate alone; red, ATTO495-Biotin alone 
the free ATTO495-Biotin (498 nm, red line), concomitant with a remarkable quenching of fluorescence to approximately $10 \%$ of the original free ligand, was observed. A similar quenching phenomenon was also reported in the specific binding of biotin-fluorescein towards avidin in neutral $\mathrm{pH}$ buffer solution [30].

\section{Discussion}

The reaction between TCO- and MTZ-groups can proceed efficiently in buffers of physiological $\mathrm{pH}$ using a small excess molar amount of the reagents relative to the molecule to be modified. Therefore, it provides a good opportunity of site-specific chemical conjugations for attaching valuable molecules, such as expensive low molecular-weight compounds or a variety of biomolecules including precious functional proteins [21]. In this study, we investigated the possibilities of the site-specific conjugation of an hFasLECD derivative with sulfo-Cy3 fluorochrome, avidin and rabbit Fab'-domain as the model experiments.

Two alternative types of sulfo-Cy3 conjugated hFasLECD were obtained using 1.3-1.4 excess molar amounts of either MTZ-group or TCO-group containing derivatives of sulfo-Cy3. These sulfo-Cy3 group containing reagents are fairly stable in physiological $\mathrm{pH}$ buffer conditions, and are commercially available at the comparable prices to the corresponding maleimide derivatives. In general, the maleimide derivatives of fluorochromes, such as fluorescein-5-maleimide, are recommended to use a large molar excess amount, typically 25-fold molar excess amount, for the efficient conjugation with free thiol groups in cysteine residues of the target proteins [31]. The obtained conjugation products in the present study showed sound fluorescence emission spectra derived from the attached sulfo-Cy3 groups together with the retention of the strong hFasRECD-Fc binding activity. This proved the possibility of less expensive derivatization of hFasLECD with valuable fluorochromes, although some decrease in the conjugation number resulted from the two step conjugation procedures, composed of the first introduction of either TCOor MTZ-group into the hFasLECD derivative and the following conjugation of the fluorochrome using the TCO - MTZ reaction, should be taken into account.

In regard to the modification of hFasLECD-TCO with protein molecules, i.e. avidin-MTZ and rFab'-MTZ, significant amounts of the conjugation products were produced in the reaction mixtures using 1.0 to $3.0 \mathrm{M}$ excess amounts of avidin-MTZ and 1.0 to $5.0 \mathrm{M}$ excess amounts of rFab'-MTZ. The isolated samples showed a strong hFasRECD-Fc binding activity as well as the functional and the structural integrities of the other component in the conjugation products. These results revealed that the conjugation of both avidin and rFab' domain to
hFasLECD in parallel with maintaining the original functions of both protein components was possible using relatively small excess molar excess amounts of the derivative of each protein, via the reaction between TCO - MTZ groups. However, considerably larger amounts of the remaining non-conjugated molecules were observed in the reaction mixtures consisted of nearly equivalent molar amounts of the TCO- and the MTZ- components as compared to the case of mPEG-MTZ. The results indicated that the conjugation reactions of hFasLECD-TCO with the MTZ derivatives of the proteins did not always proceed quantitatively, which required an efficient isolation step of the conjugated products for further characterization. This suggested that a steric hindrance derived from the bulky three-dimensional structures of the proteins became a substantial restriction factor for the efficiency of the TCO-MTZ reactions in the actual protein-protein conjugations.

The site-specific sulfo-Cy3 conjugates of hFasLECD may be useful for the evaluation of the cell-surface density of hFasR including that expressed on cancer cells, which might reflect the therapeutic response to clinical cytotoxic drugs [11-14]. The conjugation methodology toward the hFasLECD derivative using the TCO - MTZ reaction should also be applicable to other useful fluorochromes for the quantification of cell-surface receptors by flow cytometry. The receptor binding event is essentially based on the direct hFasRECD recognition function of hFasLECD in native states. Thus, the applications are considered to be suitable for the fluorescent detection of cell-surface hFasR in viable cells, which can eliminate the background and the false positive reactions derived from the modifications of cell surface caused by fixation [32, 33]. Concerning the modifications with functional proteins, the possible conjugation with Fab' fragments and other related domains of monoclonal antibodies specific to surface antigens will provide an opportunity for the targeting of hFasLECD to diseased cells. The avidin-hFasLECD conjugate holds the potential to bind any biotin conjugated molecules, such as biotinylated monoclonal antibodies targeted to malignant cells. The avidin-hFasLECD conjugate may be also applicable to enzyme-linked immunosorbent assays in cooperation with biotin conjugated enzymes. Taken together, the above application possibilities of sitespecific chemical conjugates of hFasLECD as novel molecular tools will lead to the development of the improved diagnostic systems and the effective treatment methods toward serious disorders, in which the cellsurface $h F a s R$ plays critical roles $[1,34,35]$.

\section{Conclusions}

In this study, we devised a new fundamental procedure for the preparation of site-specific chemical conjugates 
of hFasLECD with a valuable low molecular-weight compounds and precious functional proteins using the TCO - MTZ conjugation reaction. The chemical reaction required much less molar excess amount of the molecules to be conjugated as compared to the conventional thiol - maleimide reaction used in the previous study [20]. The isolated samples maintained the functional and the structural integrities of both components in the conjugates, which will lead to the development of novel molecular tools with potentials for various medical applications.

\section{Methods}

\section{Materials}

A gene of hFasLECD (amino acid residues, 139-281) containing double substitution mutations (N184Q and N250Q) with an N-terminal FLAG-(LysLysLysGlyCysGlyGlyGlyGly) tag sequence (NFK3G1CG4-hFasLECD) was constructed by introducing nine nucleotide bases (AAGAAGAAG) insertion mutation into the gene of NFG1CG4-hFasLECD. The production of NFK3G1CG4hFasLECD in a $P$. pastoris secretory expression system was conducted as described previously [19]. hFasRECDFc was produced in a baculovirus - Bombyx mori expression system and purified as described in the previous paper [36]. Avidin from egg white (for biochemistry), normal rabbit IgG whole molecule (purified by Protein A), Pepsin from porcine stomach, 2aminoethanethiol hydrochloride salt and washing buffer reagents used in the immunoprecipitation experiments were obtained from Wako Pure Chemicals, Ind. Biotin conjugated goat anti-rabbit IgG H\&L (ab207995) and ATTO495-Biotin were from Abcam Co. and ATTO-TEC GmbH, respectively.

TCO-PEG3-MAL, MTZ-PEG4-MAL, mPEG-MTZ, MTZ-PEG4-sNHS, Sulfo-Cy3-MTZ, TCO-Amine and MTZ-PEG4-Amine were purchased from Click Chemistry Tools. Sulfo-Cy3-TCO was from AAT Bioquest, Inc. A product of Protein $G$ conjugated magnetic beads (SureBeads Protein G) was obtained from Bio-Rad Laboratories. A high-performance size-exclusion chromatography column (Superdex 200 Increase 10/300 GL, bed dimensions: $10 \times 300 \mathrm{~mm}$, bed volume: approximately $24 \mathrm{ml}$ ) was purchased from GE healthcare. Other chemical reagents and devices of biochemical grade were as described in the previous paper [20]. Chemical structures were drawn using $\mathrm{ACD} /$ Chemsketch (Free ware) 2016.1.1. A densitometry analysis of the protein bands on an SDS-PAGE gel was performed using Image J [37].

In the following experiments, all protein sample concentration was conducted using an Amicon Ultra 15 [molecular-weight cut off (MWCO): $10 \mathrm{kDa}$ ] device by the centrifugation of $5000 \mathrm{G}$ at $277 \mathrm{~K}$. The sizeexclusion chromatography fractionation by a disposable column in gravity-flow mode was performed using a PD-10 column (GE healthcare). High-performance sizeexclusion chromatography was carried out using a Superdex 200 Increase 10/300 GL column under the conditions of $50 \mathrm{mM}$ tris-hydrochloride containing $150 \mathrm{mM}$ sodium chloride (pH 7.5) $[50 \mathrm{mM}$ Tris- $\mathrm{HCl}$ plus $150 \mathrm{mM} \mathrm{NaCl}(\mathrm{pH} 7.5)]$ as the elution buffer and flow rate of $0.75 \mathrm{ml} / \mathrm{min}$. In these conditions, the peak retention time of Ovalbumin $(43 \mathrm{kDa})$, Aldolase $(158 \mathrm{kDa})$ and Thyrogloblin $(669 \mathrm{kDa})$ was $20.10 \mathrm{~min}$, $17.73 \mathrm{~min}$ and $12.61 \mathrm{~min}$, respectively. All sample solutions of the TCO- and MTZ-groups containing compounds were kept frozen at $253 \mathrm{~K}$ until use. Protein concentration was determined by a BCA protein assay kit using bovine serum albumin as the standard sample. SDS-PAGE analyses were performed using a 10-20\% gradient gel and the protein bands were visualized by silver stain.

\section{Preparation of TCO- and MTZ-derivatives of NFK3G1CG4- hFasLECD}

The NFK3G1CG4-hFasLECD sample used for the preparation of either TCO- or MTZ-derivative was purified by a cation-exchange column chromatography (Hi-Trap SP, $5 \mathrm{ml}$ ) as described [19]. The protein concentration of the purified sample was determined to be $9.1 \mathrm{mg} / \mathrm{ml}$. Freshly prepared twenty-fold molar excess amount each of TCO-PEG3-MAL and MTZ-PEG4-MAL in dehydrated dimethyl sulfoxide (dry DMSO) was used for the modification reactions to obtain the TCO- and MTZderivatives, respectively. Other details in experimental procedures were the same as described for the preparation of fluorescein 5-maleimide derivative in the previous paper [20], except for the substitution of the final purification step using the high-performance sizeexclusion chromatography with the concentration step after the second size-exclusion chromatography in a gravity-flow mode. Typically, final recovery yields of the purified samples were $5.9 \mathrm{mg}$ and $6.9 \mathrm{mg}$ with respect to the TCO-derivative (hFasLECD-TCO) and the MTZderivatives (hFasLECD-MTZ) starting from $12 \mathrm{mg}$ each of the purified NFK3G1CG4-hFasLECD samples, respectively.

\section{Reactions of hFasLECD-TCO with mPEG-MTZ}

Twenty $\mu \mathrm{l}(50 \mu \mathrm{g}, 2.8 \mathrm{nmoles}$ as the monomer subunit) each of hFasLECD-TCO $(2.5 \mathrm{mg} / \mathrm{ml})$ in $50 \mathrm{mM}$ sodium acetate $(\mathrm{pH}$ 5.5) was mixed with $1.4 \quad \mu l$ (0.5 M excess), $2.8 \mu \mathrm{l}$ (1.0 M excess), $3.1 \mu \mathrm{l}$ (1.1 M excess) or $4.1 \mu \mathrm{l}(1.5$, molar excess) of mPEG-MTZ (5 kDa) solution ( $5 \mathrm{mg} / \mathrm{ml}$ in deionized water). The reaction mixture was incubated for $1 \mathrm{~h}$ at $297 \mathrm{~K}$, and then subjected to an SDS-PAGE analysis. 


\section{Preparation of sulfo-Cy3 conjugated NFK3G1CG4- hFasLECDs}

For the conjugation with sulfo-Cy3-MTZ, $3.3 \mathrm{ml}$ (5.5 mg, $0.30 \mu$ mole as the monomer subunit) of hFasLECD-TCO solution in $50 \mathrm{mM}$ sodium acetate ( $\mathrm{pH} 5.5)$ was mixed with $330 \mu \mathrm{l}(0.41 \mu$ mole, a $1.4 \mathrm{M}$ excess amount) of sulfo-Cy3-MTZ solution (1.1 $\mu$ moles / $\mathrm{ml}$ in deionized water). The reaction mixture was incubated for $1 \mathrm{~h}$ at $297 \mathrm{~K}$. The same procedure was conducted using $3.3 \mathrm{ml}(6.5 \mathrm{mg}, 0.36 \mu$ mole as the monomer subunit) of hFasLECD-MTZ solution in $50 \mathrm{mM}$ sodium acetate $(\mathrm{pH} 5.5)$ and $436 \mu \mathrm{l}(0.48 \mu$ mole, a 1.3 M excess amount) of sulfo-Cy3-TCO solution (1.1 $\mu$ moles / $\mathrm{ml}$ in deionized water) for the conjugation of sulfo-Cy3-TCO. In either case, the reaction mixture after the incubation period was immediately resolved by two tandem steps of the chromatography in a gravity flow mode using $50 \mathrm{mM}$ sodium acetate $(\mathrm{pH} 5.5)$ as the elution buffer. In the first resolving step, the reaction mixture sample was divided into two equivalent volume aliquots for a single application to the column, and one $\mathrm{ml}$ each fraction was collected into the reservoirs. The combined early four fractions eluted as pink, clear solutions were concentrated to approximately $2.0 \mathrm{ml}$. Then, the concentrate was subjected to the second resolving step for removing the remaining low molecular-weight contaminants completely. Finally, the sample was purified by the high performance size-exclusion chromatography. A $230 \mu \mathrm{l}$ each aliquot of the sample was applied to the column in an individual run. The single main peak fractions showing the absorbance of $280 \mathrm{~nm}$ and $550 \mathrm{~nm}$ at the identical retention time were collected. The fractionated samples were combined and concentrated to a fluorescent deep pink, clear solution. The final recovery yield and the protein concentration in parenthesis were $2.8 \mathrm{mg}(1.3 \mathrm{mg} / \mathrm{ml})$ and $3.1 \mathrm{mg}$ (0.92 $\mathrm{mg} / \mathrm{ml})$ with regard to Sulfo-Cy3-MT-hFasLECD and Sulfo-Cy3-TM-hFasLECD, respectively. The samples were kept frozen at $253 \mathrm{~K}$ in the dark until use, and then subjected to the SDS-PAGE analyses, the spectroscopic measurements and the experiments for the detection of complex formation with hFasRECD-Fc using the coimmunoprecipitation and the high-performance sizeexclusion chromatography analyses.

\section{Preparation of avidin-hFasLECD}

Avidin-hFasLECD was synthesized by the conjugation of Avidin-MTZ with hFasLECD-TCO. Avidin-MTZ (Fig. 1b) was prepared by the reaction of a commercially available biochemical grade avidin from chicken egg-white with eightfold molar excess amount of MTZ-PEG4-sNHS as follows. Ten $\mathrm{mg}$ of avidin was dissolved in $2.0 \mathrm{ml}$ of $0.1 \mathrm{M}$ sodium hydrogen carbonate ( $\mathrm{pH}$ 8.3), then $75 \mu \mathrm{l}$ of MTZ-PEG4-sNHS solution (2 $\mathrm{mg}$ in $200 \mu \mathrm{l}$ deionized water) prepared immediately before the reaction was added. The reaction mixture was incubated for $4 \mathrm{~h}$ at $301 \mathrm{~K}$. After that, the reaction mixture was quenched with $140 \mu \mathrm{l}$ of $1 \mathrm{M}$ Tris $\mathrm{HCl}(\mathrm{pH} 7.5)$ and further incubated for $15 \mathrm{~min}$. The quenched sample was resolved by the size-exclusion chromatography in a gravity-flow mode using $50 \mathrm{mM}$ Tris- $\mathrm{HCl}$ plus $150 \mathrm{mM} \mathrm{NaCl}(\mathrm{pH}$ 7.5) as the elution buffer. The same resolution step was repeated again to remove the low molecular-weight contaminants containing MTZ group completely. The recovered sample was concentrated to $2.4 \mathrm{ml}$ (4.3 $\mathrm{mg} / \mathrm{ml})$ of a pale pink, clear solution, and used as the sample for the following conjugation reactions.

Initial attempts of the conjugation reaction between Avidin-MTZ and hFasLECD-TCO were performed by mixing $10 \mu \mathrm{l}, 20 \mu \mathrm{l}$ or $30 \mu \mathrm{l}$ of hFasLECD-TCO solution [2.52 $\mathrm{mg} / \mathrm{ml}$ in $50 \mathrm{mM}$ sodium acetate $(\mathrm{pH} 5.5)]$ with a series (1.0, 1.2, 1.5 or $3.0 \mathrm{M}$ excess amount) of AvidinMTZ solutions $[4.3 \mathrm{mg} / \mathrm{ml}$ in $50 \mathrm{mM}$ Tris- $\mathrm{HCl}$ plus $150 \mathrm{mM} \mathrm{NaCl}(\mathrm{pH} \mathrm{7.5)}$ ], and incubated for $1 \mathrm{~h}$ at $301 \mathrm{~K}$. Each reaction mixture was diluted to $200 \mu \mathrm{l}$ with $50 \mathrm{mM}$ Tris- $\mathrm{HCl}$ plus $150 \mathrm{mM} \mathrm{NaCl}(\mathrm{pH} \mathrm{7.5)}$ buffer, and then subjected to an analysis using the high performance size-exclusion chromatography. A large scale conjugation reaction under the condition of 1.5 fold excess molar amount of Avidin-MTZ relative to hFasLECDTCO was conducted by mixing $1.1 \mathrm{ml}$ (2.7 mg, 70 nmoles) of Avidin-MTZ solution with $1.0 \mathrm{ml}$ (2.5 mg, 46 nmoles) of hFasLECD-TCO solution. The reaction mixture was incubated for $1 \mathrm{~h}$ at $299 \mathrm{~K}$, and then quenched with $23 \mu \mathrm{l}$ of $30 \mathrm{mM}$ TCO-Amine solution $(3.9 \mathrm{mg}$ in $0.5 \mathrm{ml}$ of deionized water) by incubating for further $1 \mathrm{~h}$. The final colorless, clear reaction mixture after the quenching reaction was applied to a single step of the size-exclusion chromatography in a gravity-flow mode to remove the low molecular-weight contaminants, and then $230 \mu \mathrm{l}$ aliquots of the recovered sample were resolved by the high performance size-exclusion column chromatography to obtain single peak fractions. All isolated fractions were combined together and concentrated to $1.4 \mathrm{ml}$ for the analyses in the following experiments (recovery yield, $1.5 \mathrm{mg}$ ).

\section{Preparation of rFab'-hFasLECDs}

rFab'-hFasLECDs were synthesized by the conjugation of rFab'-MTZ with hFasLECD-TCO. The rFab' domain was obtained essentially according to the procedures described in the previous papers [38, 39]. Thirty five mg of the commercially available Protein A purified normal rabbit IgG whole molecule in $3.5 \mathrm{ml}$ of $0.1 \mathrm{M}$ sodium acetate containing $0.1 \mathrm{M}$ sodium chloride buffer (pH 4.5) was digested with $1.6 \mathrm{mg}$ of Pepsin from porcine stomach by incubating for $20 \mathrm{~h}$ at $310 \mathrm{~K}$ 
(Additional file 3a). The sample after the digestion was subjected to exchange the buffer with $50 \mathrm{mM}$ Tris- $\mathrm{HCl}$ plus $150 \mathrm{mM} \mathrm{NaCl}$ (pH 7.5) by the size-exclusion column chromatography in a gravity-flow mode. Then, $230 \mu \mathrm{l}$ aliquots of the sample were further fractionated by the high performance size-exclusion chromatography using the same buffer (Additional file 3b, left panel). The main peak fractions containing $\mathrm{rF}\left(\mathrm{ab}^{\prime}\right)_{2}$ were collected and combined to total sample volume of $32.0 \mathrm{ml}$. The sample was concentrated to $3.6 \mathrm{ml}(5.4 \mathrm{mg} / \mathrm{ml})$. To a half volume of this sample solution containing $9.8 \mathrm{mg}$ $(0.21 \mu$ mole $)$ of $\mathrm{rF}\left(\mathrm{ab}^{\prime}\right)_{2}, 48 \mu \mathrm{l}$ of $0.5 \mathrm{M}$ ethylenediaminetetraacetic acid sodium salt (EDTA-Na) (pH 8.0) and $240 \mu \mathrm{l}$ of freshly prepared $100 \mathrm{mM} \mathrm{2-aminoethantiol}$ hydrochloride solution in $50 \mathrm{mM}$ Tris- $\mathrm{HCl}$ containing $10 \mathrm{mM}$ EDTA-Na (pH 7.5) were added and incubated for $30 \mathrm{~min}$ at $310 \mathrm{~K}$, for the conversion of $\mathrm{rF}\left(\mathrm{ab}^{\prime}\right)_{2}$ to rFab'. Then, the reaction mixture was immediately subjected to a size-exclusion chromatography column preequilibrated with $25 \mathrm{mM}$ sodium phosphate containing $0.1 \mathrm{M}$ sodium chloride and $5 \mathrm{mM}$ EDTA-Na ( $\mathrm{pH}$ 6.4) for buffer-exchange. The sample containing rFab' was diluted to $9.7 \mathrm{ml}$ with the same buffer, and freshly prepared MTZ-PEG4-MAL solution [10 mg (19 $\mu$ moles) in $0.97 \mathrm{ml}$ of dry DMSO] was added. The reaction mixture was incubated for $3 \mathrm{~h}$ at $297 \mathrm{~K}$, and then quenched with $22 \mu \mathrm{l}$ of $1 \mathrm{M}$ L-cysteine hydrochloride solution in deionized water by incubating further $1 \mathrm{~h}$. The quenched reaction mixture was concentrated to $2.0 \mathrm{ml}$, and further subjected to the two tandem sizeexclusion chromatography in a gravity-flow mode to remove the MTZ-group containing low molecularweight contaminants completely. After that, the highperformance size-exclusion chromatography resolutions of $230 \mu \mathrm{l}$ aliquots were performed to obtain the main peak fractions of rFab'-MTZ sample (Additional file $3 \mathrm{~b}$, right panel). The collected samples were combined and concentrated to $3.0 \mathrm{ml}$ of pale pink, clear solution (recovery yield $6.9 \mathrm{mg}, 2.3 \mathrm{mg} / \mathrm{ml}$ ).

Initial attempts of the conjugation reaction between rFab'-MTZ and hFasLECD-TCO were performed by mixing $10 \mu \mathrm{l}$ each of hFasLECD-TCO solution [2.5 $\mathrm{mg} / \mathrm{ml}$ in $50 \mathrm{mM}$ sodium acetate ( $\mathrm{pH} 5.5)]$ with a series $(1.0,2.0,3.0$ or $5.0 \mathrm{M}$ excess amount) of rFab'-MTZ solutions $[2.3 \mathrm{mg} / \mathrm{ml}$ in $50 \mathrm{mM}$ Tris$\mathrm{HCl}$ plus $150 \mathrm{mM} \mathrm{NaCl}(\mathrm{pH}$ 7.5)] and incubated for $1 \mathrm{~h}$ at $298 \mathrm{~K}$. Each reaction mixture was diluted to $200 \mu \mathrm{l}$ with $50 \mathrm{mM}$ Tris- $\mathrm{HCl}$ plus $150 \mathrm{mM} \mathrm{NaCl}$ ( $\mathrm{pH}$ 7.5) buffer for subjecting to an analysis by the high-performance size-exclusion column chromatography. Large scale conjugation reactions under the condition of $1.0 \mathrm{M}$ excess and $5.0 \mathrm{M}$ excess amounts of rFab'-MTZ relative to hFasLECD were conducted by mixing $1.2 \mathrm{ml}(2.7 \mathrm{mg}, 58 \mathrm{nmoles})$ of rFab'-MTZ solution with $1.3 \mathrm{ml}$ (3.2 mg, 60 nmoles) of hFasLECDTCO solution, and $1.5 \mathrm{ml}$ (3.4 mg, 72 nmoles) of rFab'MTZ solution with $0.31 \mathrm{ml}(0.78 \mathrm{mg}, 14$ nmoles $)$ of hFasLECD-TCO solution, respectively. Both reaction mixtures were incubated for $1 \mathrm{~h}$ at $298 \mathrm{~K}$, and then quenched by incubating for further $1 \mathrm{~h}$ with $19 \mu \mathrm{l}$ (in the $1.0 \mathrm{M} \mathrm{ex}$ cess amount reaction) and $4.8 \mu \mathrm{l}$ (in the $5.0 \mathrm{M}$ excess amount reaction) of $30 \mathrm{mM}$ MTZ-PEG4-Amine solutions (5.0 $\mathrm{mg}$ in $0.42 \mathrm{ml}$ of deionized water), respectively. The final pale pink, clear solutions were subjected to the sizeexclusion chromatography in a gravity mode. Then, $230 \mu \mathrm{l}$ aliquots were resolved using the high-performance sizeexclusion column chromatography to obtain the fractionated samples. The isolated sample fractions combined together were concentrated to $1.0 \mathrm{ml}(0.57 \mathrm{mg})$ and $0.88 \mathrm{ml}(0.13 \mathrm{mg})$ with regard to the reaction using $1.0 \mathrm{M}$ excess amount of rFab'-MTZ and that using the $5.0 \mathrm{M}$ excess amount of rFab'-MTZ, respectively.

\section{Preparation of the complex between avidin-hFasLECD and ATTO495-biotin}

$1.2 \mathrm{ml}(1.2 \mathrm{mg})$ of the isolated avidin-hFasLECD conjugate was mixed with $40 \mu \mathrm{l}$ of ATTO495-Biotin solution ( $1 \mathrm{mg}$ in $100 \mu \mathrm{l}$ of Dry DMSO) and incubated for $2 \mathrm{~h}$ on ice. The mixture was resolved by the two tandem steps of chromatography in a gravity-flow mode in order to completely remove the free ATTO495-Biotin. The sample recovered in the second resolving step $(0.84 \mathrm{mg}$, $240 \mu \mathrm{g} / \mathrm{ml}$ ) was subjected to the experiment for detection of the complex.

\section{Spectroscopic measurements and estimation of conjugation number of sulfo-Cy3}

UV-Vis absorption spectra in the range from $250 \mathrm{~nm}$ to $650 \mathrm{~nm}$, a couple of independent measurements of absorption values at $280 \mathrm{~nm}$ and $552 \mathrm{~nm}$ used for the calculation of an estimated conjugation number of sulfo-Cy3 groups to hFasLECD and fluorescent spectra measurement under the condition of the excitation wavelength at $552 \mathrm{~nm}$ were performed as described in the previous paper [20]. All measurements were conducted under the sample concentrations of $125 \mu \mathrm{g} / \mathrm{ml}$. In the calculation of the estimated conjugation number, the correction factor of sulfo-Cy3 group at $280 \mathrm{~nm}$ was set to 0.05 , and the molar extinction coefficient of sulfoCy3 group was assumed as 150,000 [40]. The molar extinction coefficient of NFK3G1CG4-hFasLECD was obtained as 29,005 using the Prot Param tool on the EXPAsy Server [41].

\section{Detection of the complex formation}

Detection of the specific binding activity of the isolated conjugates, i.e. sulfo-Cy3-hFasLECDs, AvidinhFasLECD and rFab'-hFasLECDs, and the components 
of the conjugates, i.e. hFasLECD-TCO, Avidin-MTZ and rFab'-MTZ, (5.5 $\mu \mathrm{g}$ each) toward either the hFasRECD-Fc sample $(8.8 \mu \mathrm{g})$ or biotin conjugated goat anti-rabbit IgG H\&L $(14.0 \mu \mathrm{g})$ were conducted using a Protein G conjugated magnetic beads $(1.0 \mathrm{mg})$ as the precipitating agent by the receptoror the antibody-mediated co-immunoprecipitation in $1.0 \mathrm{ml}$ of $50 \mathrm{mM}$ Tris- $\mathrm{HCl}$ plus $150 \mathrm{mM} \mathrm{NaCl}$ buffer $(\mathrm{pH} 7.5)$ containing $1 \%$ Nonidet $\mathrm{P} 40$ and $0.5 \%$ sodium deoxycholate, as described in the previous paper [25]. Another experiment for the detection of the complex formation between sulfo-Cy3-hFasLECDs and hFasRECD-Fc was also performed by the highperformance size-exclusion chromatography using the mixture solutions composed of sulfo-Cy3-hFasLECDs (7.5 $\mu \mathrm{g}$ each) and hFasRECD-Fc $(19.4 \mu \mathrm{g})$ in $230 \mu \mathrm{l}$ solution as described in the previous paper [20]. The UV-Vis spectra of the isolated complex sample of Avidin-hFasLECD conjugate with ATTO495-Biotin and the Avidin-hFasLECD conjugate alone sample were compared at the concentration of $240 \mu \mathrm{g} / \mathrm{ml}$ in $50 \mathrm{mM}$ Tris- $\mathrm{HCl}$ plus $150 \mathrm{mM} \mathrm{NaCl}$ (pH 7.5). A solution of free ATTO495-Biotin showing the absorbance value at $495 \mathrm{~nm}(0.29)$ similar to that of the isolated complex sample (0.26) was also subjected to measurement for comparison of the absorption peak profiles.

\section{Additional files}

Additional file 1: Preparation of NFK3G1CG4-hFasLECD. a) Gene structure of expression unit and detailed tag sequences. In the tag sequences, the introduced three lysine residues and the reactive cysteine residue used for chemical modification with either TCOPEG3-MAL or MTZ-PEG4-MAL are shown in blue and red, respectively. AOX-1 P, P. pastoris alcohol oxidase 1 promoter region; a-Prepro, Saccharomyces cerevisiae a-factor secretion-signal sequence; Tag, tag sequence; hFasLECD (139-281, N184Q, N250Q), human Fas ligand extracellular domain containing deletion mutation from residue 103 to 138 and double substitution mutation (N184Q and N250Q); AOX-1 $\Pi$, P. pastoris alcohol oxidase 1 transcription termination region. b) Three dimensional structure of hFasLECD-hDcR3 complex [26]. A biological unit image composed of a single hFasLECD trimer (yellow) and a triply bound hDcR3 monomer (white) is depicted as space filling models. The $\mathrm{N}$-terminal residues of hFasLECD subunits in this model are shown in green. Left panel, a horizontal view. One of the position of $\mathrm{N}$-terminal tag sequence attachment sites is arrowed. Right panel, a vertical view. The structure was drawn using the atomic coordinates (ID: 4smv) and the graphic software $(\mathrm{j} V$ ) provided by Protein Data Bank Japan (PDBj). C) SDS-PAGE analysis of initial stepwise salt-gradient fractionation of the materials in $P$. pastoris culture medium using a cation-exchange column (Hi-Trap S $5 \mathrm{ml}$ ). Basal buffer: $50 \mathrm{mM}$ sodium acetate (pH 5.5). Lanes: M, Molecular-weight size markers; 1 , before fractionation; 2, flow-through fraction; 3, $0 \mathrm{mM} \mathrm{NaCl}$ fraction; 4, $50 \mathrm{mM} \mathrm{NaCl}$ fraction; 5, $300 \mathrm{mM} \mathrm{NaCl}$ fraction; 6, $500 \mathrm{mM} \mathrm{NaCl}$ fraction. AOX-1: P. pastoris alcohol oxidase 1, hFasLECD dimer: disulfide-bridged dimer of hFasLECD subunits, hFasLECD monomer: monomeric hFasLECD subunit. (PPTX $333 \mathrm{~kb}$ )

Additional file 2: High-performance size-exclusion chromatography profile of hFasRECD-Fc. Absorbance at $280 \mathrm{~nm}$ (blue) and $550 \mathrm{~nm}$ (red) was used for the detection. (PPTX $88 \mathrm{~kb}$ )
Additional file 3: Preparation of rFab'-MTZ. a) SDS-PAGE analysis of pepsin digestion of whole rabbit lgG. Lanes: $\mathrm{M}$, molecular-weight size markers; 1, before digestion; 2, after digestion. b) Fractionation by highperformance size-exclusion chromatography. Panels: left, $r F\left(a b^{\prime}\right)_{2}$, peak fraction shown in the underbar was collected; right, rFab'-MTZ, peak fraction shown in the underbar was collected. Retention time of each peak is shown. (PPTX $231 \mathrm{~kb}$ )

\section{Abbreviations}

hFasLECD: human Fas ligand extracellular domain; hFasRECD: human Fas receptor extracellular domain; hFasRECD-Fc: a fusion protein composed of human Fas receptor extracellular domain and human $\lg _{1}-\mathrm{Fc}$ domain; MTZ: 6-methyl-1, 2, 4, 5-tetrazine group; NaCl: sodium chloride; SDS-PAGE: sodium dodecyl sulfate polyacrylamide gel-electrophoresis; TCO: trans-cyclooctene group; Tris-HCl: tris(hydroxymethyl)aminomethane hydrochloride

\section{Acknowledgements}

The authors thank the persons in charge of inquiries about the commercial products used in this study for providing detailed information on them.

\section{Funding}

This work was supported by a grant for operating expenses from the Ministry of Economy, Trade and Industry, Japan.

\section{Availability of data and materials}

The authors declare that all relevant data are included in the article and its additional files.

\section{Authors' contributions}

MM designed the study, performed experiments, and wrote the manuscript. $\mathrm{MM}$ and $\mathrm{KH}$ analyzed and interpreted the experimental data. All authors read and approved the final manuscript.

Ethics approval and consent to participate

Not applicable.

Consent for publication

Not applicable.

\section{Competing interests}

The authors declare that they have no competing interests.

\section{Publisher's Note}

Springer Nature remains neutral with regard to jurisdictional claims in published maps and institutional affiliations.

Received: 5 April 2017 Accepted: 27 June 2017

Published online: 03 July 2017

\section{References}

1. Nagata S. Fas ligand-induced apoptosis. Annu Rev Genet. 1999;33:29-55.

2. Yanting Z, Huang B, Shi J. Fas ligand and lytic granule differentially control cytotoxic dynamics of natural killer cell against cancer target. Oncotarget. 2016;7:47163-72.

3. Bremer E. Targeting of the tumor necrosis factor receptor superfamily for cancer immunotherapy. ISRN Oncol. 2013; doi:10.1155/2013/371854.

4. Muraki M. Disulfide-bridged proteins with potential for medical applications: therapeutic relevance, sample preparation and structure - function relationships. Integr Mol Med. 2014;1:38-56. doi:10.15761/IMM1000109.

5. Tanaka M, Suda T, Yatomi T, Nakamura N, Nagata S. Lethal effect of recombinant human Fas ligand in mice pretreated with Propionibacterium acnes. J Immunol. 1997;158:2303-9.

6. Villa-Morales M, Fernández-Piqueras J. Targeting the Fas/FasL signaling pathway in cancer therapy. Expert Opin Ther Targets. 2012;16:85-101. doi:10.1517/14728222.2011.628937.

7. Wajant H, Gerspach J, Pfizenmaier K. Engineering death receptor ligands for cancer therapy. Cancer Lett. 2013;332:163-74. doi:10.1016/j.canlet. 2010.12.019. 
8. Chan DV, Sharma R, Ju CYA, Roffler SR, Ju ST. A recombinant scFv-FasLext as a targeting cytotoxic agent against human Jurkat-Ras cancer. J Biomed Sci. 2013;20:16. doi:10.1186/1423-0127-20-16.

9. Aronin A, Amsili S, Prigozhina TB, Tzdaka K, Shen R, Grinmann L, Szafer F, Edebrink P, Rauvola MA, Shani N, Elhalel MD. Highly efficient, in-vivo Fas-mediated apoptosis of B-cell lymphoma by hexameric CTLA-FasL. J Hematol Oncol. 2014;7:64. doi:10.1186/s13045-014-64-6.

10. Chien MH, Chang WM, Lee WJ, Chang YC, Lai TC, Chan DV, Sharma R, Lin YF, Hsiao M. A Fas ligand (FasL)-fused humanized antibody against tumor-associated glycoprotein 72 selectively exhibits the cytotoxic effect against oral cancer cells with a low FasL/Fas ratio. Mol Cancer Ther. 2017;16:1102-13. doi:10.1158/1535-7163.MCT-16-0314.

11. Micheau O, Solary E, Hammann A, Martin F, Dimanche-Boitrel MT. Sensitization of cancer cells treated with cytotoxic drugs to Fas-mediated cytotoxity. J Natl Cancer Inst. 1997;89:783-9.

12. $X u X, F u X Y$, Plate J, Chong ASF. IFN- $\gamma$ induces cell growth inhibition by Fas-mediated apoptosis: requirement of STAT1 protein for up-regulation of Fas and FasL expression. Cancer Res. 1998;58:2832-7.

13. Yang D, Torres CM, Bardhan K, Zimmermann M, McGaha TL, Liu K Decitabine and vorinostat cooperate to sensitize colon carcinoma cells to Fas ligand-induced apoptosis in vitro and tumor suppression in vivo. J Immunol. 2012;188:4441-9.

14. Galenkamp KMO, Carriba P, Urresti J, Planells-Ferrer L, Coccia E, LopezSoriano J, Barneda-Zahonero B, Moubarak RS, Segura MF, Comella JX. TNFa sensitizes neuroblastoma cells to FasL-, cisplatin- and etoposide-induced cell death by NF-kB-mediated expression of Fas. Mol Cancer. 2015;14:62. doi:10.1186/s12943-015-0329-X.

15. Komada Y, Inaba H, Li OS, Azuma E, Zhou YW, Yamamoto H, Sakurai M. Epitopes and functional responses defined by a panel of anti-Fas (CD95) monoclonal antibodies. Hybridoma. 1999;18:391-8.

16. Lacour S, Hammann A, Grazide S, Lagadic-Gossmann D, Athias A, Sergent O, Laurent G, Gambert P, Solary E, Dimanche-Boitrel MT. Cisplatin-induced CD95 redistribution into membrane lipid rafts of HT29 human colon cancer cells. Cancer Res. 2004;64:3593-8.

17. Charker JM, Bernardes GJL, Davis BG. A "tag-and-modify" approach to siteselective protein modification. Acc Chem Res. 2011;44:730-41. doi:10.1021/ ar20005q.

18. Rader C. Chemically programmed antibodies. Trends Biotechnol. 2014;32: 186-97. doi:10.1016/j.tibtech.2014.02.003.

19. Muraki M. Improved production of recombinant human Fas ligand extracellular domain in Pichia pastoris: yield enhancement using disposable culture-bag and its application to site-specific chemical modifications. BMC Biotechnol. 2014;14:19. doi:10.1186/1472-6750-14-19.

20. Muraki M. Preparation of a functional fluorescent human Fas ligand extracellular domain derivative using a three-dimensional structure guided site-specific fluorochrome conjugation. SpringerPlus. 2016:5:997. doi:10.1186/s40064-016-2673-8.

21. Wu H, Devaraj NK. Inverse electron-demand Diels-Alder bioorthogonal reactions. Top Curr Chem (Z). 2016;374:3. doi:10.1007/s41061-015-0005-z

22. Selvaraj R, Fox JM. trans-Cyclooctene - a stable. voracious dienophile for bioorthogonal labeling. Curr. Opin. Chem Biol. 2013;17:753-60. doi:10.1016/j. cbpa.2013.07.031.

23. Knall AC, Slugovc C. Inverse electron demand Diels-Alder (iEDDA)-initiated conjugation: a (high) potential click chemistry scheme. Chem Soc Rev. 2013; 42:5131-42. doi:10.1039/c3cs60049a.

24. Muraki M. Secretory expression of synthetic human Fas ligand extracellular domain gene in Pichia pastoris: influences of tag addition and Nglycosylation site deletion, and development of a purification method. Protein Expr Purif. 2006;50:137-46. doi:10.1016/j.pep.2006.08.006.

25. Muraki M. Improved secretion of human Fas ligand extracellular domain by $\mathrm{N}$-terminal part truncation in Pichia pastoris and preparation of the $\mathrm{N}$-linked carbohydrate chain trimmed derivative. Protein Expr Purif. 2008;60:205-13. doi:10.1016/j.pep.2008.03.027

26. Liu W, Ramagopal U, Cheng H, Bonanno JB, Toro R, Bhosle R, Zhan C, Almo SC. Crystal structure of the complex of human FasL and its decoy receptor DcR3. Structure. 2016;24:2016-23. doi:10.1016/j.str.2016.09.009.

27. Schröder AK, Nardella FA, Mannik M, Svensson ML. Interaction between streptococcal lgG Fc receptors and human and rabbit lgG domains. Immunology. 1986;57:305-9.

28. Goat anti-rabbit lgG H\&L (Biotin) (ab207995). http://www.abcam.co.jp/goatrabbit-igg-hl-biotin-ab207995.html Accessed Mar 292017.
29. Lee $H G$, Fritsche E. Determination of biotin on a protein by quantitative sodium dodecyl sulfate - capillary gel electrophoresis of monomeric avidin. J Chromatogr A. 2003;994:213-9. doi:10.1016/S0021-9673(03)00440-0.

30. Kada G, Falk H, Gruber HJ. Accurate measurement of avidin and streptavidin in crude biofluids with a new, optimized biotin - fluorescein conjugate. Biochim Biophys Acta. 1999;1427:33-43.

31. Hermanson GT. Fluorescent probes. In: Bioconjugate techniques (third edition) chapter 10. London: Academic Press; 2013. p. 395-463.

32. Posner MR, Antoniou D, Griffin J, Schlossman SF, Lazarus H. An enzymelinked immunosorbent assay (ELISA) for the detection of monoclonal antibodies to cell surface antigens on viable cells. J Immunol Methods. 1982;48:23-31

33. Grunow R, D'Apuzzo M, Wyss-Coray T, Frutig K, Pichler WJ. A cell surface ELISA for the screening of monoclonal antibodies to antigens on viable cells in suspension. J Immunol Methods. 1994:171:93-102.

34. De la Rosa AJ, Gomez MA, Morales S, Padillo FJ, Muntane J. CD95 signaling in cancer treatment. Curr Pharm Des. 2014:20:2809-18.

35. Modiano JF. Fas ligand based immunotherapy: a potent and effective neoadjuvant with checkpoint inhibitor properties, or a systemically toxic promoter of tumor growth? Discov Med. 2016;21:109-16.

36. Muraki M, Honda S. Efficient production of human Fas receptor extracellular domain - human lgG1 heavy chain Fc domain fusion protein using baculovirus/silkworm expression system. Protein Expr Purif. 2010;73:209-16. doi:10.1016/j.pep.2010.05.007.

37. Schneider CA, Rasband WS, Eliceiri KW. NIH image to ImageJ: 25 years of image analysis. Nat Methods. 2012;9:671-5.

38. Crivianu-Gaita $V$, Romaschin A, Thompson M. High efficiency reduction capability for the formation of Fab' antibody fragments from $\mathrm{F}(\mathrm{ab})_{2}$ units. Biochem Biophys Rep. 2015;2:23-8. doi:10.1016/j.bbrep.2015.04.004.

39. Makaraviciute A, Jackson CD, Millner PA, Ramanaviciene A. Considerations in producing preferentially reduced half-antibody fragments. J Immunol Methods. 2016;429:50-6. doi:10.1016/j.jim.2016.01.001.

40. Cy3 Methyltetrazine, Click Chemistry Tools (product number: 1018). https://clickchemistrytools.com/wp-content/uploads/2016/08/1018-infosheet.pdf. Accessed 29 Mar 2017.

41. Gasteiger E, Hoogland C, Gattiker A, Duvaud S, Willkins MR, Appel RD, Bairoch A. Protein identification and analysis tools on EXPAsy Server. $\mathrm{n}$ : Walker JM, editor. The proteomics protocols handbook. Totowa: Humana Press; 2005. p. 571-607.

\section{Submit your next manuscript to BioMed Central and we will help you at every step:}

- We accept pre-submission inquiries

- Our selector tool helps you to find the most relevant journal

- We provide round the clock customer support

- Convenient online submission

- Thorough peer review

- Inclusion in PubMed and all major indexing services

- Maximum visibility for your research

Submit your manuscript at www.biomedcentral.com/submit 